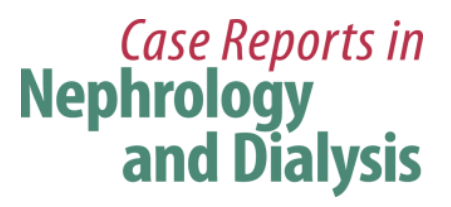

Case Rep Nephrol Dial 2017;7:73-80

DOI: $10.1159 / 000477662$

Publisned onIIne: June 23, 2017

(C) 2017 The Author(s)

Published by S. Karger AG, Basel

www.karger.com/cnd

This article is licensed under the Creative Commons Attribution-NonCommercial 4.0 International License (CC BY-NC) (http://www.karger.com/Services/OpenAccessLicense). Usage and distribution for commercial purposes requires written permission.

\title{
A Toddler Presenting with Pulmonary Renal Syndrome
}

\author{
Florence A. Aeschlimann ${ }^{a} \quad$ Rae S.M. Yeung ${ }^{a} \quad$ Ronald M. Laxer \\ Diane Hebert $^{b} \quad$ Ashley Cooper $^{c}$ Rose Chami ${ }^{d}$ Damien Noone ${ }^{b}$ \\ ${ }^{a}$ Division of Rheumatology, The Hospital for Sick Children and University of Toronto, \\ Toronto, ON, Canada; ${ }^{b}$ Division of Nephrology, The Hospital for Sick Children and \\ University of Toronto, Toronto, ON, Canada; 'Division of Rheumatology, \\ Children's Mercy - Kansas City, Kansas City, MO, USA; ${ }^{d}$ Department of Paediatric \\ Laboratory Medicine, Hospital for Sick Children, and Department of Laboratory \\ Medicine and Pathobiology, University of Toronto, Toronto, ON, Canada
}

\section{Keywords}

Palpable purpura $\cdot$ Pulmonary hemorrhage $\cdot$ Proteinuria $\cdot$ Hematuria

\begin{abstract}
Pulmonary renal syndrome refers to an association of pulmonary and glomerular disease and includes disorders, such as the ANCA-associated vasculitides, anti-glomerular basement membrane antibody disease, systemic lupus erythematosus, and IgA vasculitis (HenochSchönlein purpura). We present the medical history of a 26 -month-old boy with an extensive purpuric rash, involving the limbs, trunk, and face, who developed clinically significant pulmonary hemorrhage and renal involvement. Rapid recognition of this rare but potentially life-threatening condition is crucial. In this report, we discuss the differential diagnosis, diagnostic studies, and treatment options to consider when facing a young child presenting with a pulmonary renal syndrome.

(C) 2017 The Author(s)

Published by S. Karger AG, Basel
\end{abstract}




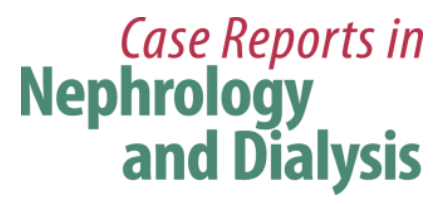

Case Rep Nephrol Dial 2017;7:73-80

DOI: $10.1159 / 000477662$

(C) 2017 The Author(s). Published by S. Karger AG, Base www.karger.com/cnd

Aeschlimann et al.: A Toddler Presenting with Pulmonary Renal Syndrome

\section{Introduction}

Pulmonary renal syndrome describes the association of severe pulmonary and renal disease and includes disorders, such as the anti-neutrophil cytoplasmic antibody (ANCA)associated vasculitides, anti-glomerular basement membrane (GBM) antibody disease, systemic lupus erythematosus (SLE), and IgA vasculitis (IgAV, Henoch-Schönlein purpura [HSP]) [1]. Pulmonary renal syndrome rarely occurs in children; however, its prompt diagnosis is critical to minimize the high disease-related morbidity and mortality [1]. This report describes a toddler with pulmonary renal syndrome, who completely recovered with supportive treatment and immunosuppressive drugs.

\section{Case Presentation}

A 26-month-old toddler presented with a 1-day history of purpuric rash on the lower limbs, arthralgia, and swelling of his face, ankles, knees, hands, and genitalia. Blood work, urinalysis, and chest X-ray were unremarkable. A diagnosis of IgAV (HSP) was made and conservative management recommended. A few days later he presented with tachypnea, shortness of breath, and severe respiratory distress but was afebrile and normotensive. There was palpable purpura on his extremities, trunk, and face (Fig. 1) with significant scalp edema. Laboratory investigations revealed a hemoglobin of $54 \mathrm{~g} / \mathrm{L}$, white blood cells of $5.9 \times$ $10^{9} / \mathrm{L}$ with normal differentiation, platelets of $229 \times 10^{9} / \mathrm{L}$, erythrocyte sedimentation rate of $19 \mathrm{~mm} / \mathrm{h}$ (normal range 2-12), C-reactive protein of $4.7 \mathrm{mg} / \mathrm{L}$ (normal range 0.1-1.0), albumin of $28 \mathrm{~g} / \mathrm{L}$ (normal range 37-50), and normal creatinine and blood urea nitrogen. Coombs test was negative. Urinalysis showed microhematuria (50-100 erythrocytes/hpf) with granular (1-4/hpf) and hyaline casts (1-4/hpf), but no proteinuria at this stage. During intubation for respiratory distress, blood was seen in the airways. Chest X-ray and computed tomography showed extensive bilateral patchy opacities. In view of the clinical and radiologic findings, he was diagnosed with pulmonary hemorrhage.

Bronchoalveolar lavage (BAL) showed no hemosiderin-laden macrophages or acute bleeding, but diffusely blood-tinged mucus, and a diagnosis of IgAV (HSP)-associated pulmonary hemorrhage was assumed. Two blood transfusions were required, and he received intravenous methylprednisolone $(30 \mathrm{mg} / \mathrm{kg}$ ) for 4 days followed by methylprednisolone 2 $\mathrm{mg} / \mathrm{kg} /$ day. Although plasmapheresis and pulse cyclophosphamide were considered, these were deferred following his improvement with high-dose corticosteroids. Further investigations revealed negative anti-nuclear antibody (ANA), ANCA and anti-GBM antibody screen, and normal complement levels. Due to increased blood-tinged secretions, bronchoscopy was repeated 1 week later and identified the right lower lobe as the site of bleeding. There was focal inflammation and Moraxella catarrhalis was isolated from BAL on this occasion (likely ventilator-associated pneumonia), which was treated by antibiotics. He further improved on prednisone, and additional immunosuppression was not initiated. He developed mild proteinuria (protein $1 \mathrm{~g} / \mathrm{L}$ on urine dipstick); however, renal biopsy was deferred due to his critically ill clinical status. He was ventilated for 12 days and discharged on prednisone treatment after 17 days. A few days later, he developed right knee arthritis. He became hypertensive, was started on amlodipine, and referred to our nephrology clinic where a renal 


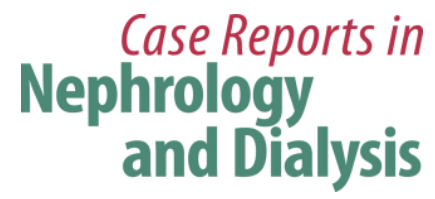

Case Rep Nephrol Dial 2017;7:73-80

biopsy was performed due to persistent proteinuria $(1 \mathrm{~g} / \mathrm{L}$, protein/creatinine ratio 77.7 $\mathrm{mg} / \mathrm{mmol}$ ). Histopathology revealed involvement of $10 \%$ of 23 glomeruli with segmental lesions showing both active and chronic changes (Fig. 2). Immunofluorescence demonstrated diffuse segmental granular staining of mesangial regions with some capillary loops for IgG $(2+)$, IgA (3+), and C3 (3+), confirming IgAV (HSP) nephritis (Fig. 3). This corresponded to the ISKDC histological classification of IgA vasculitis grade IIIa - focal mesangial proliferation with $<50 \%$ crescents.

He was started on enalapril and azathioprine. Prednisone was tapered and discontinued at 17 months, and azathioprine was discontinued at 24 months after disease onset. At 36 months' follow-up, he remains very well, now off enalapril, with no evidence of proteinuria, hypertension, or disease activity.

\section{Discussion}

This child presented with an extensive purpuric vasculitic rash, pulmonary hemorrhage, and microhematuria. Even though he had no signs of overt glomerular disease at onset, microhematuria indicated renal involvement and his findings were suggestive of a pulmonary renal syndrome, an uncommon entity which can be divided into both specific and nonspecific etiologies. "Specific" pulmonary renal syndrome refers to an association of pulmonary and glomerular disease and includes disorders such as the ANCA-associated vasculitides (granulomatosis with polyangiitis [GPA], microscopic polyangiitis, or eosinophilic granulomatosis with polyangiitis), anti-GBM antibody (Goodpasture) disease, SLE, and IgAV (HSP). The term nonspecific pulmonary renal syndrome describes pulmonary disease following pre-existent renal disease or vice versa [1]. Co-existence of pulmonary and renal disease has been described in the ANCA-associated vasculitides, most frequently in GPA, in which granulomatous multisystem inflammation is commonly found in the ear, nose, and throat (75-96\%), pulmonary $(80-84 \%)$, and renal system $(79-88 \%)[2,3]$. GPA manifests mostly during adolescence; disease onset in toddlers is extremely rare [3]. Anti-GBM antibody disease typically presents with a rapidly progressive glomerulonephritis accompanied by pulmonary hemorrhage, is confirmed by the presence of circulating anti-GBM antibodies, and is exceedingly rare in children $[2,4]$. SLE usually manifests in adolescent girls with typical cutaneous, musculoskeletal, cardiovascular, and central nervous system symptoms associated with hematologic abnormalities and classical antibodies. Renal involvement occurs in 48-100\% during the course of disease [2]. Pulmonary involvement, such as pleuritis, pneumonitis, and abnormal pulmonary function testing, is relatively common in SLE; however, the occurrence of pulmonary hemorrhage is an unusual manifestation [2]. IgAV (HSP) is the most common systemic vasculitis in childhood. The diagnosis is based on the European League Against Rheumatism (EULAR)/Paediatric Rheumatology International Trials Organisation (PRINTO)/Paediatric Rheumatology European Society (PReS) classification criteria and requires at least one of the four following criteria in addition to the mandatory criterion of nonthrombocytopenic purpura: abdominal pain, typical histopathology, arthritis or arthralgia, and renal involvement [5]. While IgA (HSP)-associated nephritis occurs in approximately $30 \%$ of patients [6], pulmonary hemorrhage is rare in IgAV (HSP) $(<1 \%)$ [7] and has primarily been reported in adults, where it is associated with a significant morbidity and mor- 
tality [8]. Symptoms can be mild and hemoptysis is absent in 33\% of the patients. Therefore, a high level of suspicion is needed in patients with only mild respiratory symptoms or a sudden drop of the hemoglobin [9].

Besides basic laboratory testing, more specific investigations are recommended in the presence of a pulmonary renal syndrome (Table 1 ).

In the acute setting of a pulmonary renal syndrome, especially in the absence of a disease-defining autoantibody such as ANCA, a bronchoscopy with BAL should be considered to aid diagnosis and exclude a possible infection before treatment initiation. Frankly bloody or blood-tinged BAL fluid suggests pulmonary hemorrhage. Hemosiderin-laden macrophages may be demonstrated in BAL fluid $48 \mathrm{~h}$ following the onset of pulmonary hemorrhage [10]. A tissue biopsy may be obtained to confirm the diagnosis. In IgAV (HSP), a biopsy is indicated only in children with an unusual presentation or significant renal disease. While a tissue biopsy from skin or kidney in a patient with IgAV (HSP) is classically characterized by a leukocytoclastic vasculitis of small vessels or proliferative glomerulonephritis with IgA deposition, the lung biopsy might reveal only alveolar hemorrhage without capillaritis and variable presence of IgA deposits along the alveolar septa $[6,8]$. In our patient, antibody testing was negative, BAL revealed blood-tinged fluid, and kidney biopsy revealed classical findings of IgAV (HSP)-nephritis including IgA deposits.

For IgA (HSP)-associated pulmonary hemorrhage, no standard treatment has been established, and recommendations are based on retrospective series. Chen et al. [11] reviewed treatment and outcome of 17 children with IgA (HSP)-associated pulmonary hemorrhage and concluded that aggressive treatment including high-dose corticosteroids and pulse cyclophosphamide should be considered for children with respiratory failure as mortality in this group was high (33\%). The optimal treatment strategies for IgA (HSP) nephritis are controversial [6]. Noncontrolled studies have shown beneficial effects of immunosuppressive drugs including azathioprine [6]. However, data on immunosuppressive treatment other than corticosteroids are limited in IgAV (HSP) nephritis.

\section{Conclusion}

The pulmonary renal syndromes are often associated with severe and life-threatening underlying systemic diseases. Pulmonary hemorrhage in IgAV (HSP) is very rare in childhood-onset IgAV (HSP) $(<1 \%)$ and tends to occur in older patients. Because symptoms can be mild and hemoptysis absent, a high level of suspicion is needed in patients with only mild respiratory symptoms or a sudden drop of the hemoglobin.

The literature regarding optimal treatment of IgA (HSP)-associated pulmonary hemorrhage is scarce. The available data suggest aggressive treatment with prednisone and pulse cyclophosphamide for both children and adults, especially if respiratory failure is present. However, our patient had an excellent outcome on monotherapy with high-dose prednisone even though he presented with respiratory failure, which raises the question as to whether aggressive treatment is needed for all children with IgAV (HSP)-related pulmonary hemorrhage. 


\section{Acknowledgements}

F.A.A. was supported by grants from the Rhyner-Bangerter Foundation, StarrFoundation, Swiss League against Rheumatism, and Foundation W!

\section{Statement of Ethics}

Informed consent and permission to publish the pictures were obtained from the patient's family.

\section{Disclosure Statement}

The authors declare that they have no conflict of interest.

\section{References}

-1 von Vigier RO, Trummler SA, Laux-End R, Sauvain MJ, Truttmann AC, Bianchetti MG: Pulmonary renal syndrome in childhood: a report of twenty-one cases and a review of the literature. Pediatr Pulmonol 2000;29:382-388.

2 Petty R, Laxer RM, Lindsley CB, Wedderburn LR (eds): Textbook of Pediatric Rheumatology, ed 7. Philadelphia, Elsevier, 2016.

-3 Cabral DA, Uribe AG, Benseler S, O’Neil KM, Hashkes PJ, Higgins G, et al: Classification, presentation, and initial treatment of Wegener's granulomatosis in childhood. Arthritis Rheum 2009;60:3413-3424.

4 Greco A, Rizzo MI, De Virgilio A, Gallo A, Fusconi M, Pagluica G, Martellucci S, Turchetta R, Longo L, De Vincentiis M: Goodpasture's syndrome: a clinical update. Autoimmun Rev 2015;14:246-253.

-5 Ozen S, Pistorio A, Iusan SM, Bakkaloglu A, Herlin T, Brik R, et al: EULAR/PRINTO/PRES criteria for Henoch-Schonlein purpura, childhood polyarteritis nodosa, childhood Wegener granulomatosis and childhood Takayasu arteritis: Ankara 2008. Part II: Final classification criteria. Ann Rheum Dis 2010;69:798-806.

6 Davin JC, Coppo R: Henoch-Schonlein purpura nephritis in children. Nat Rev Nephrol 2014;10:563-573.

7 McCarthy HJ, Tizard EJ: Clinical practice: Diagnosis and management of Henoch-Schonlein purpura. Eur J Pediatr 2010;169:643-650.

-8 Rajagopala S, Shobha V, Devaraj U, D’Souza G, Garg I: Pulmonary hemorrhage in Henoch-Schonlein purpura: case report and systematic review of the English literature. Semin Arthritis Rheum 2013;42:391-400.

Schwarz MI, Brown KK: Small vessel vasculitis of the lung. Thorax 2000;55:502-510.

10 Sherman JM, Winnie G, Thomassen MJ, Abdul-Karim FW, Boat TF: Time course of hemosiderin production and clearance by human pulmonary macrophages. Chest 1984;86:409-411.

11 Chen SY, Chang KC, Yu MC, Asueh S, Ou LS: Pulmonary hemorrhage associated with Henoch-Schonlein purpura in pediatric patients: case report and review of the literature. Semin Arthritis Rheum 2011;41:305-312. 


\section{Case Reports in Nephrology and Dialysis}

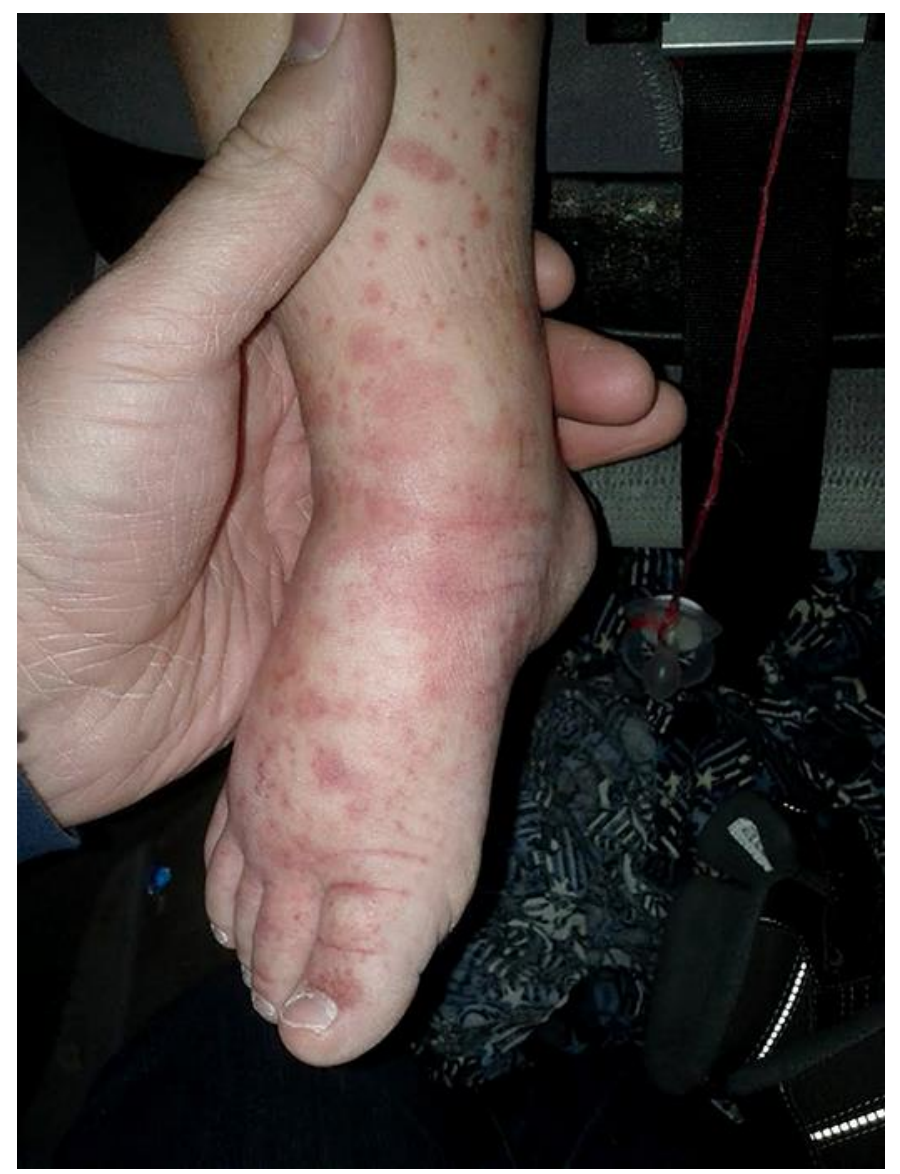

Fig. 1. A purpuric rash was seen on the extremities, the trunk, and the face. Note the swelling of the foot. 


\section{Case Reports in Nephrology and Dialysis}

(C) 2017 The Author(s). Published by S. Karger AG, Basel www.karger.com/cnd

Aeschlimann et al.: A Toddler Presenting with Pulmonary Renal Syndrome

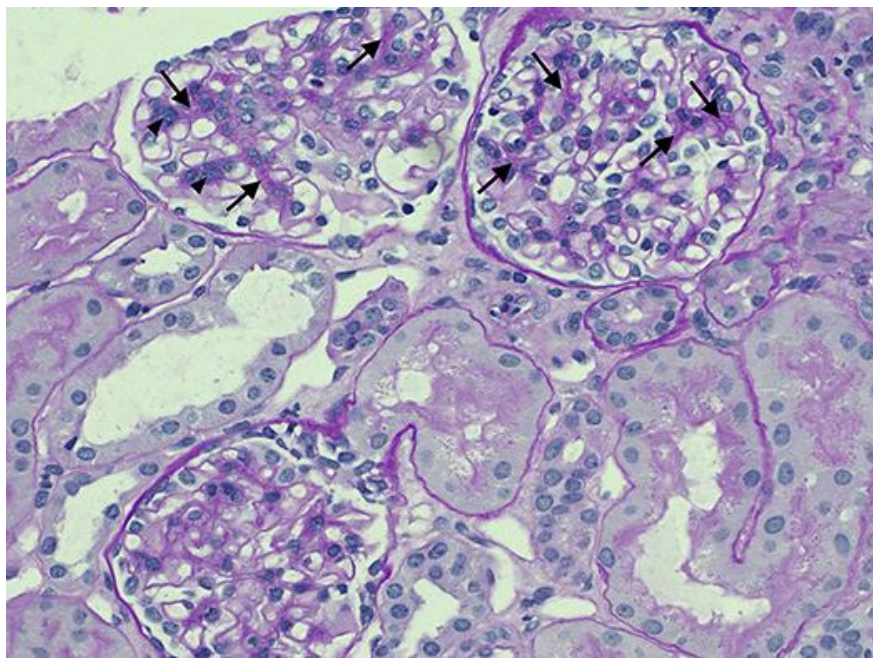

Fig. 2. Representative image of light microscopy of the kidney biopsy. Mild segmental increase in mesangial cellularity and matrix. PAS stain. $\times 200$. The arrowheads show the mild increase in mesangial cellularity and matrix, the arrows highlight the minimal to mild increase in mesangial matrix.

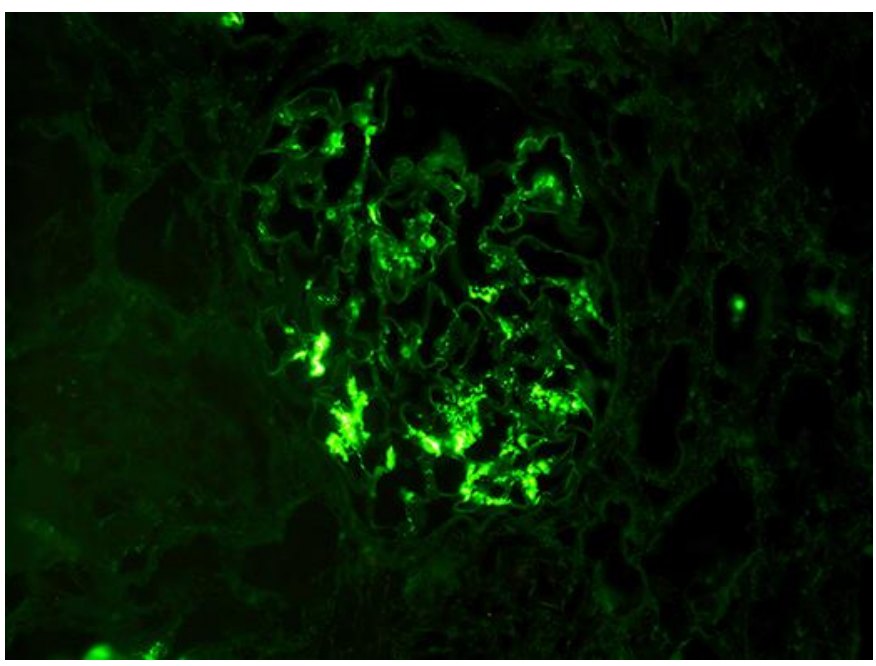

Fig. 3. Immunofluorescence staining of the kidney biopsy. Segmental granular staining of mesangial regions and rare capillary walls for IgA. $\times 200$. 

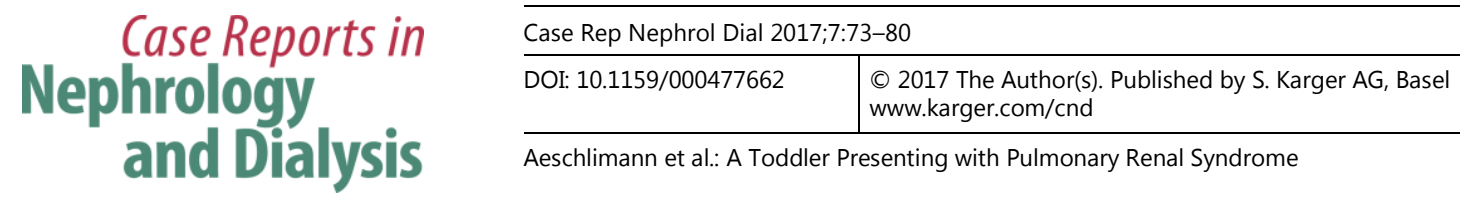

Table 1. Laboratory tests recommended in a child with pulmonary renal syndrome

\begin{tabular}{ll}
\hline ANA & Present in virtually all children with SLE though nonspecific \\
\hline ANCA & $\begin{array}{l}\text { ANCA with cytoplasmic immunofluorescence staining pattern } \\
\text { (c-ANCA) are present in } 90 \% \text { of children with GPA, 70\% have } \\
\text { specificity for PR3 } \\
\text { ANCA with perinuclear staining pattern (p-ANCA) and } \\
\text { specificity for MPO are present in 75\% of children with MPA }\end{array}$ \\
\hline Anti-GBM antibodies & Present in >95\% of patients with anti-GBM antibody disease \\
\hline Complement levels (C3, C4) & Reduced in SLE and post-streptococcal glomerulonephritis \\
\hline $\begin{array}{l}\text { ANA, anti-nuclear antibodies; SLE, systemic lupus erythematosus; ANCA, anti-neutrophilic cytoplasmic } \\
\text { antibodies; GPA, granulomatosis with polyangitis; PR3, proteinase 3; MPO, myeloperoxidase; MPA, } \\
\text { microscopic polyangiitis; anti-GBM antibodies, anti-glomerular basement membrane antibodies. }\end{array}$ \\
\hline
\end{tabular}

